\title{
Reconstrução e impressão 3D do neurocrânio de cão com o uso de tomografia computadorizada como ferramenta para auxiliar no ensino da anatomia veterinária
}

[Reconstruction and three-dimensional printing $(3 D)$ of the neurocranium of a dog from computed tomography used as a tool for anatomy veterinary teaching]

\section{J.V.P. Bertti ${ }^{1}$, E.E. Silveira ${ }^{2}$, A.C. Assis Neto ${ }^{3 *}$}

${ }^{1}$ Aluno de graduação - Faculdade de Medicina Veterinária e Zootecnia - Universidade de São Paulo - São Paulo, SP

${ }^{2}$ Aluno de pós-graduação - Faculdade de Medicina Veterinária e Zootecnia - Universidade de São Paulo - São Paulo, SP

${ }^{3}$ Faculdade de Medicina Veterinária e Zootecnia - Universidade de São Paulo - São Paulo, SP

\section{RESUMO}

A impressão tridimensional (3D) vem contribuindo para o aprendizado da anatomia e para áreas aplicadas da medicina veterinária utilizando uma interface que pode valorizar o conhecimento da anatomia das espécies domésticas de maneira dinâmica. O presente trabalho objetivou utilizar imagens tridimensionais geradas por tomografias computadorizada (TC) para a obtenção de imagens digitalizadas e de modelos de ossos do crânio de cão por meio de uma impressora tridimensional. Foram gerados arquivos $3 \mathrm{D}$ de TC a partir de imagens que foram editadas pelo software Osirix Lite. Partes dos ossos e particularidades anatômicas do crânio foram impressas em escalas de $60 \%$ e $100 \%$. Os resultados permitiram gerar imagens digitalizadas e impressões tridimensionais advindas das tomografias, e, assim, foi criado um acervo de imagens e modelos impressos para os estudos da anatomia do crânio da espécie canina. Além disso, a metodologia demonstrou claramente a importância para uso de planejamentos cirúrgicos nos casos de procedimentos que envolvam comprometimento de estruturas ósseas. Produziu-se um material interativo e impresso em 3D com maior durabilidade, o qual poderá ser disponibilizado para fins educacionais.

Palavras-chave: impressora 3D, educação em ciências anatômicas, modelos anatômicos, anatomia veterinária

\begin{abstract}
The three-dimensional printer (3D) has been contributing to the learning of anatomy and applied areas of veterinary medicine using an interface that can enhance the knowledge of the anatomy of domestic species in a dynamic way. The present study aimed to use three-dimensional images generated by computed tomography (TC) to obtain digitized images and bone models of the dog skull using a three-dimensional printer. The 3D files were generated from images that were edited in Osirix Lite software. Parts of the bones and anatomical features of the skull were printed on $60 \%$ and $100 \%$ scales. The results allowed to generate digitalized images and three -dimensional impressions from the tomographies, and in this way a collection of images and printed models was created for studies of the anatomy of the canine species. In addition, the methodology clearly demonstrated the importance of using surgical planning in cases involving procedures involving bone structure impairment. Interactive material and $3 D$ printing with high durability that could be made available for educational purposes has been produced.
\end{abstract}

Keywords: 3D printing, anatomical science education, anatomical models, veterinary anatomy

\section{INTRODUÇÃO}

Em 1984, Charles Hull fez a primeira impressora 3D, que, em vez de tinta no papel, construía objetos camada a camada. Mas foi nos últimos anos que essa tecnologia ganhou notoriedade. A utilização da impressão 3D vem contribuindo com a inovação nas áreas de engenharia, arte, indústria, educação e medicina. Hoje em dia, já é uma realidade a impressão $3 \mathrm{D}$ de biomateriais

Recebido em 6 de fevereiro de 2019

Aceito em 17 de outubro de 2019

*Autor para correspondência (corresponding author)

E-mail: antonioassis@usp.br 
compatíveis, células e componentes de suportes teciduais e anatômicos.

Os avanços na impressão 3D permitem que arquivos digitais sejam transformados em um produto físico impresso (Sander et al., 2017; Reis et al., 2019). As imagens de tomografia computadorizada, por exemplo, fornecem excelentes fontes de dados anatômicos tridimensionais (Barker et al., 1993. Esses et al., 2011; Doney et al., 2013).

A obtenção de moldes impressos em 3D já é realidade em ramos sofisticados de especialidades médicas, como a cardiologia e a ortopedia (Giannopoulos et al., 2016; Su et al., 2018). Depois de estabelecer uma indicação clínica apropriada, a impressão 3D normalmente começa com a aquisição de imagens volumétricas de alta qualidade de tomografia computadorizada (TC) ou ressonância magnética (RM) (Giannopoulos et al., 2016). Tudo isso ainda precisa evoluir e ser aplicado na medicina veterinária.

Na medicina humana, já se têm vários benefícios, como a criação de modelos de órgãos para planejamentos cirúrgicos e a produção de próteses ortopédicas e de órgãos a partir de injeções de células em modelos biodegradáveis (Atala et al., 2006). A tecnologia 3D ainda promete produzir dispositivos biomédicos complexos, de acordo com programas específicos de computador usando dados anatômicos individuais (Chia e Wu, 2015; Visser et al., 2013; Xu et al., 2013). Apesar de tudo isso, a impressão 3D ainda é uma ciência complexa, que requer equipamentos caros e sofisticados. Para abordar essas complexidades, é necessária a integração de tecnologias nos campos da engenharia, da ciência de biomateriais, da biologia celular e tecidual, de estudos anatômicos, da física e de medicamentos (Atala et al., 2006; Giannatsis e Dedoussis, 2009; Atala, 2014; Murphy e Atala (2014); Song et al., 2014; Zhang e Zhang, 2015).

O presente estudo utilizou imagens tomográficas da espécie canina, com a finalidade de criar um biomodelo ósseo do neurocrânio, e, dessa forma, disponibilizar um material interativo que contribua para o conhecimento da anatomia veterinária 3D da espécie e sua aplicação na área veterinária.

\section{MATERIAL E MÉTODOS}

O programa Osirix Lite software foi utilizado para que os exames de imagens de tomografia computadorizada das cabeças dos cães fossem editados, transformados em arquivos tridimensionais e, posteriormente, transformados em arquivos PDF "Portable Document Format" e impressos (Rosset et al., 2004).

O exame de tomografia computadorizada foi realizado no Hovet - USP (Hospital Veterinário da FMVZ - USP), em um animal da espécie canina sem raça definida.

O programa VXElements permitiu que as imagens digitalizadas fossem visualizadas no computador (Laptop - 16Gb Windows ${ }^{\circledR}$ pro 64 bits - Inglês USA/LA/Canada). O programa também permitiu algumas possibilidades de edições, como deletar partes indesejáveis da digitalização, reparar alguns defeitos na superfície, remover artefatos isolados e otimizar as imagens, todos em escala de 0 a 100 unidades. Além disso, foi possível selecionar a resolução desejada.

Os volumes obtidos das imagens da cabeça, após sua edição e transformação, foram também utilizados para a criação de imagens dinâmicas no formato PDF. A partir desses arquivos, criou-se um material didático que poderá ser utilizado em aulas de anatomia veterinária para complementar o aprendizado de alunos de graduação.

Partes dos ossos do crânio foram impressos por Stratasys Mojo Printer, que utiliza, para a impressão, um material termoplástico em forma de filamento. O método de trabalho consiste na deposição do material em uma resina de suporte que posteriormente será removida. A área de impressão mínima da impressora é de 120 x 120 x $120 \mathrm{~mm}$, espessura de camada $\leq 0,17 \mathrm{~mm}$.

A impressão pode ser realizada com o molde em várias posições (horizontal, vertical e diagonal). Os moldes podem ser impressos com seu interior sólido ou vazado, e aqui foram impressos em modo sólido, pois isso os tornava muito mais resistentes.

Depois de impressos, os moldes com a resina de suporte foram lavados, para que os resíduos fossem removidos em uma lavadora da marca Stratasys Modelo Wave Wash 55. 


\section{RESULTADOS E DISCUSSÃO}

No presente trabalho, utilizaram-se imagens de tomografia computadorizada e, com base nelas, foram criados modelos tridimensionais impressos de boa qualidade para o estudo anatômico do crânio da espécie canina. Os recursos obtidos neste trabalho tornam-se um meio de consolidação e aprofundamento da aprendizagem garantido por um acesso fácil a um material didático de qualidade, o que nem sempre é possível nos laboratórios convencionais de anatomia veterinária. Réplicas fidedignas de modelos ósseos produzidos com alta qualidade podem ser uma excelente alternativa inovadora no ensino de anatomia veterinária e um melhor delineamento em planejamento cirúrgico. Segundo Sander et al. (2017), modelos anatômicos complexos imprimíveis e derivados de exames de TC, embora tenham um grande potencial para promover a aprendizagem, ainda são pouco utilizados pelo programa acadêmico mundial.

Mediante a utilização do software Osirix Lite, as imagens tridimensionais foram obtidas de imagens de tomografia computadorizada (Fig. 1). A partir dos arquivos em formato PDF 3D (Fig. 2 e 3) foram impressos os modelos 3D de partes do crânio do cão. De acordo com Newe (2015), o "Portable Document Format (PDF)" é o formato mais eficiente para projetar dados de imagens biomédicas. Os resultados evidenciaram os detalhes anatômicos dos ossos que compõem o neurocrânio e a grande semelhança com os modelos reais obtidos por maceração óssea. Detalhes das estruturas ósseas do neurocrânio (osso parietal, temporal, zigomático e occipital), parte dorsocaudal da mandíbula e os componentes ósseos do aparelho hioide foram reconstruídos (Fig. 2). Os modelos ósseos tridimensionais impressos mostraram-se com uma boa qualidade de impressão. As particularidades dos ossos puderam ser facilmente identificadas. Os modelos foram produzidos em escala real (tamanho original - $100 \%$ ) e também em um modo mais econômico de impressão, em escala de $60 \%$ do tamanho original (Fig. 2 e 3). Modelos 3D de crânios humanos utilizados para planejamentos pré-operatórios, para fins educacionais e para atender a simuladores cirúrgicos foram testados para avaliar a qualidade do material impresso e, assim como o crânio do cão produzido no presente trabalho, verificou-se que os materiais de resina foram os que obtiveram aparência mais realista e que preservaram melhor os detalhes anatômicos (Salmi et al., 2013; McDonal et al., 2001).

Aparentemente não ocorreu diferença de qualidade de impressão quando foi avaliado o aspecto e a aparência das particularidades ósseas. A qualidade dos modelos impressos depende da qualidade dos dados da fonte de imagem. As imagens reconstruídas $(0,50-1,25 \mathrm{~mm})$ podem permitir a visualização de detalhes precisos da anatomia, mas geralmente requerem um processamento mais específico e delicado.

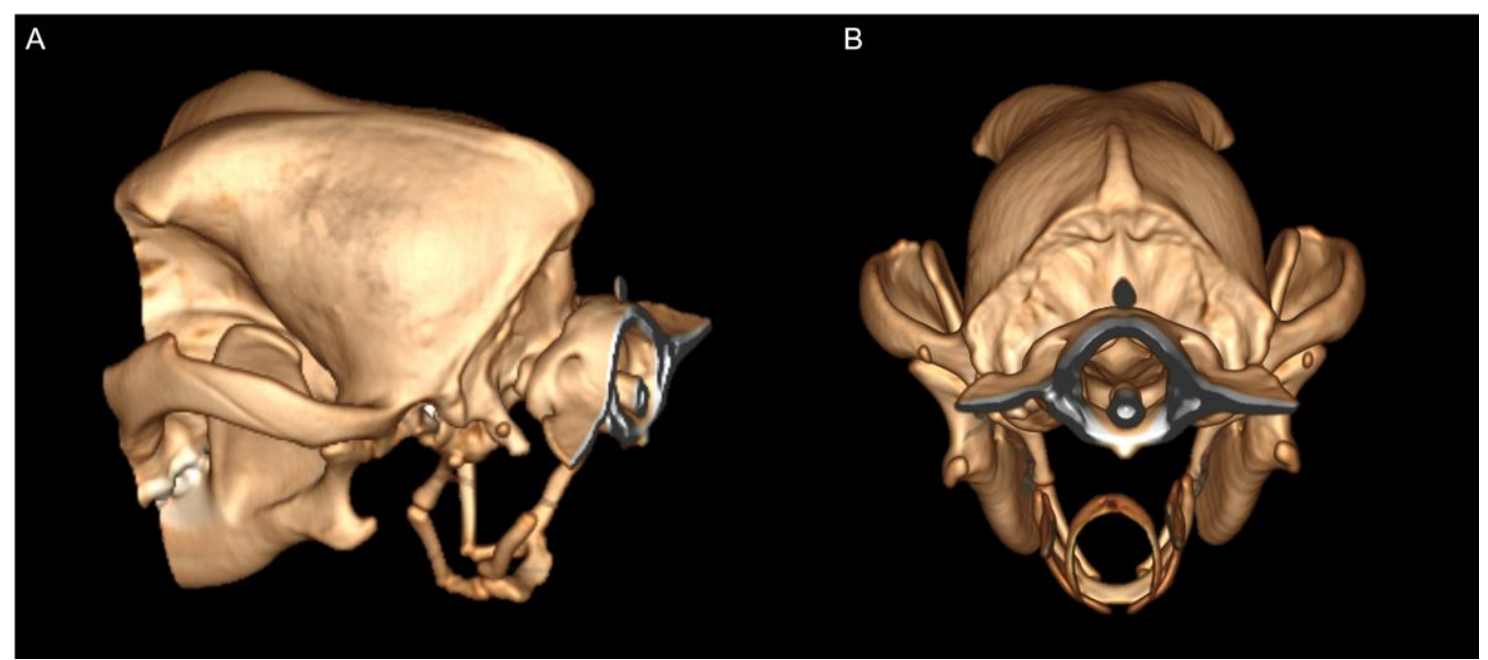

Figura 1. Reconstrução tomográfica computadorizada (TC) multiplanar da porção caudal da cabeça e início da região cervical de um cão SRD. (A) vista lateral e (B) vista dorsocaudal. 


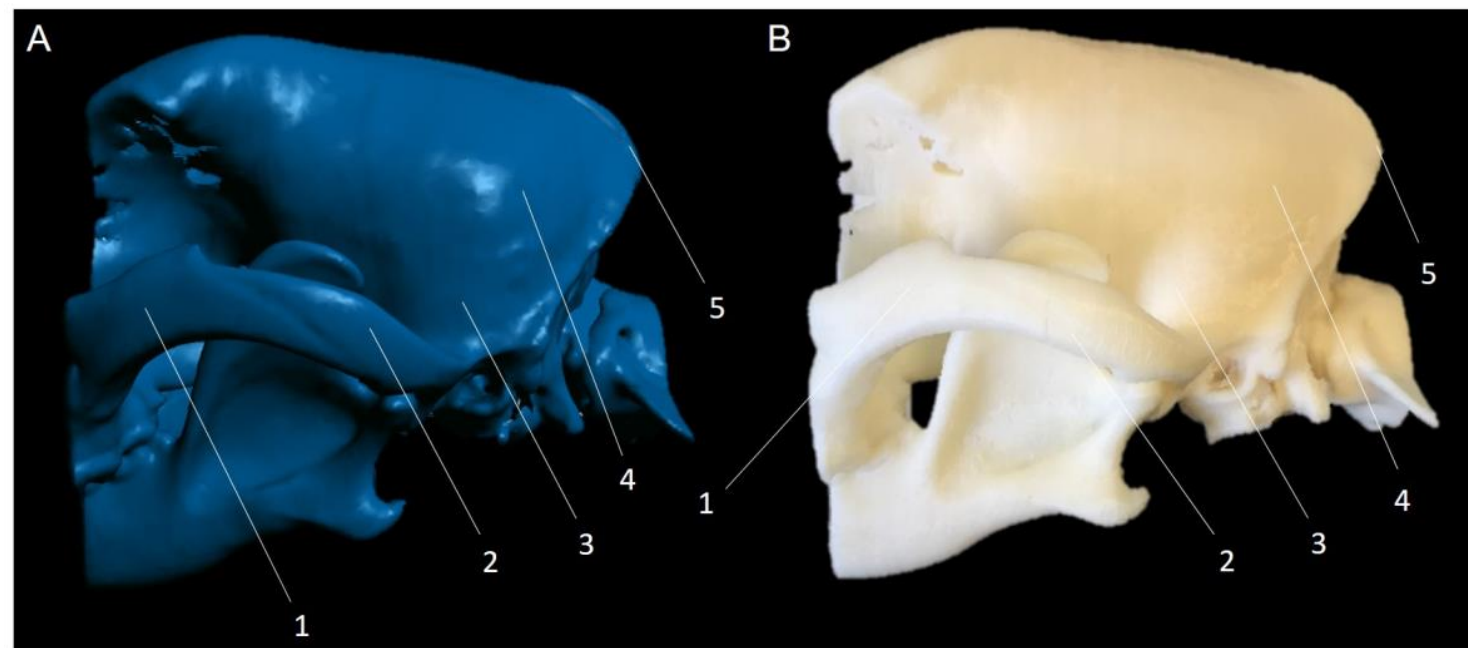

Figura 2. Representação virtual do neurocrânio canino e biomodelos impressos em 3D: Observa-se, em "A", o aspecto lateral dos ossos do crânio digitalizados e, em "B", o aspecto lateral do biomodelo 3D impresso. 1- Processo frontal do zigomático, 2- processo zigomático do temporal, 3- osso temporal, 4- osso parietal, 5- osso interparietal.

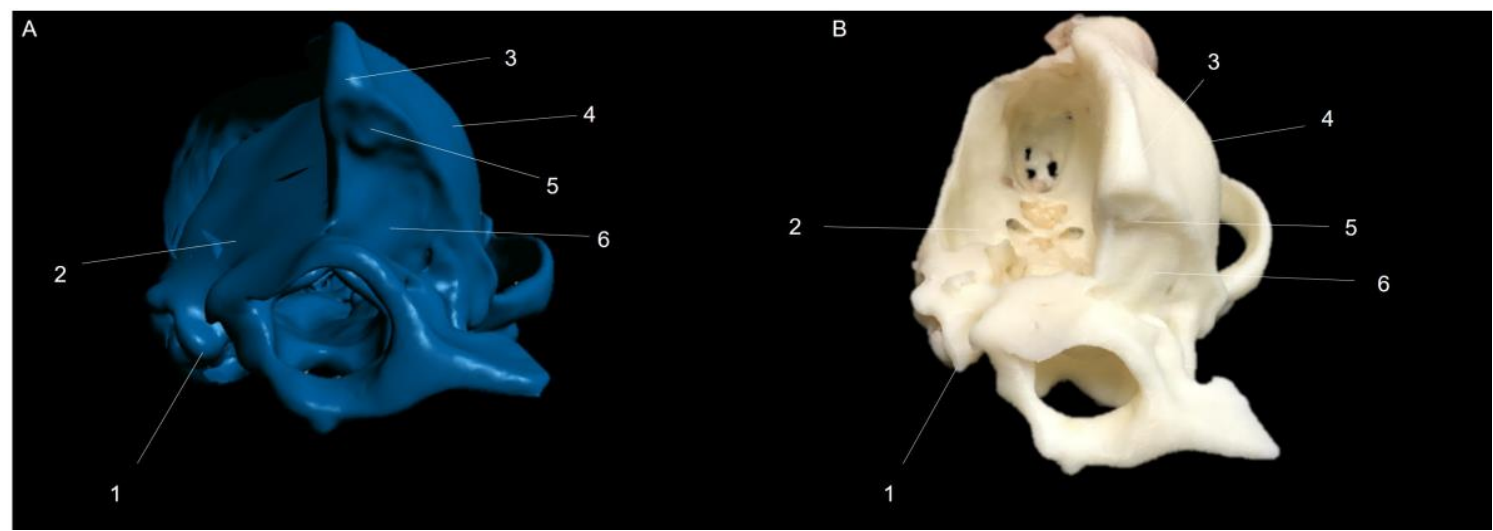

Figura 3. Representação virtual do neurocrânio canino e biomodelos impressos em 3D: Observa-se, em "A" e em "B", o aspecto caudal dos ossos digitalizados e do biomodelo 3D impresso. 1- Processo paracondilar, 2- osso temporal, 3- osso interparietal, 4- osso parietal, 5- parte escamosa do osso occipital, 6- osso occipital.

Giannopoulos et al. (2016) demonstraram que médicos e residentes tiveram um melhor entendimento dos estudos de casos de pacientes com problemas cardiovasculares quando utilizaram modelos impressos tridimensionais.

Sistemas integrados de imagens de tomografia computadorizada, associadas a dissecações macroscópicas de cadáveres e impressões 3D, podem melhorar significativamente as habilidades de estudantes de medicina e residentes de radiologia (Murakami et al., 2014). Dessa forma, o uso de crânios de cão impressos em 3D, associados com as imagens digitalizadas 3D, poderá positivamente contribuir para o aprendizado anatômico de estudantes em cursos de anatomia veterinária.

Modelos ósseos têm sido empregados com sucesso no ensino médico em universidades de diversos continentes. A tecnologia 3D será um grande desafio nas próximas décadas para as áreas médicas, no sentido de que já existe uma necessidade de desenvolvimento de novas habilidades e competências clínicas agregadas ao uso dessa tecnologia (AbouHashem et al., 2015). Atualmente já é possível imprimir materiais delicados que podem ser utilizados em 
procedimentos cirúrgicos para substituir ossos (Bergmann et al., 2010). A partir de tomografias computadorizadas, Crossinghamm et al. (2009) reconstruíram a anatomia do fígado humano para facilitar $\mathrm{o}$ entendimento $\mathrm{da}$ anatomia tridimensional do órgão. A produção de modelos com o uso de TC pode atrair a curiosidade de educadores, pesquisadores e estudantes por utilizar uma tecnologia que melhora a visualização deles e proporciona a experiência sensorial de segurar um objeto real que possa ser mantido, girado, examinado e movimentado (Doney et al., 2013). A medicina veterinária ainda tem um longo caminho para prosseguir em termos de desenvolvimento de tecnologias digitais que possam ser incorporadas no ensino e em aplicações clínicas.

O material digital e impresso em 3D, como o demonstrado no presente trabalho, contribui significativamente, do ponto de vista educacional, no sentido de criar um acervo que poderá ser eternizado nas instituições de ensino e pesquisa. Além disso, pode minimizar o uso de órgãos e de partes de animais mantidos em soluções fixadoras e conservadoras de cadáveres, que muitas vezes são compostas de substância química tóxica.

\section{CONCLUSÕES}

O processo de impressão 3D dos ossos do crânio do cão produziu imagens e réplicas fidedignas de partes do neurocrânio utilizando-se imagens de tomografias computadorizadas. Foi possível obter imagens digitalizadas de alta qualidade e impressões 3D muito condizentes com a realidade. As imagens apresentaram qualidades excelentes e podem facilmente ser utilizadas como recurso didático para fins educacionais dentro da anatomia veterinária.

\section{AGRADECIMENTOS}

AoCNPQ e a CAPES pelas bolsas ao alunos João VP Betti e Erick E Silveira e a Professora Dra. Carla Aparecida Batista Lorigados pelas imagens de TC. Aos Programas Renovalab 2013 e Próinovalab 2012 da Pró-Reitoria de Graduação da USP que apoiaram o financeiramente dos equipamentos adquiridos para os projetos.

\section{REFERÊNCIAS}

ABOUHASHEM, Y.; DAYAL, M.; SAVANAH, S.; ŠTRKALJ, G. The application of 3D printing in anatomy education. Med. Educ. Online, v.20, p. $29847,2015$.

ATALA, A. Regenerative bladder augmentation using autologous tissue-when will we get there? $J$. Urol., v.191, p.1204-1205, 2014.

ATALA, A.; BAUER, S.B.; SOKER, S. et al. Tissue-engineered autologous bladders for patients needing cystoplasty. Lancet, v.367, p.1241-1246, 2006.

BARKER, T.M.; EARWAKER, W.J.S.; FROST, $\mathrm{N}$; WAKELEY. Integration of 3-D medical imaging and rapid prototyping to create stereolithographic models. Australas. Phys. Eng. Sci. Med., v.16, p.79-85, 1993.

BERGMANN, C.; LINDNER, M.; ZHANG, W. et al. 3D printing of bone substitute implants using calcium phosphate and bioactive glasses. $J$. Eur. Ceramic Soc., v.30, p.2563-2567, 2010.

CHIA, H.N.; WU, B. Recent advances in 3D printing of biomaterials. J. Biol. Eng., v.9, p.1-14, 2015.

CROSSINGHAM, J.L.; JENKINSON, J.; WOOLRIDGE, N. et al. Interpreting threedimensional structures from twodimensional images: a web-based interactive 3D teaching model of surgical liver anatomy. $H P B$, v.11, p.523-528, 2009.

DONEY, E.; KRUMDICK, L. A.; DIENER, J.M et al. 3D printing of preclinical X-ray computed tomographic data sets. J. Vis. Exp., v.73, p.e50250, 2013.

ESSES, S.J.; BERMAN, P.; BLOOM, A.I.; SOSNA, J. Clinical applications of physical 3D models derived from MDCT data and created by rapid prototyping. AJR Am. J. Roentgenol., v.196, p.683-688, 2011.

GIANNATSIS, J.; DEDOUSSIS, V. Additive fabrication technologies applied to medicine and health care: a review. Int. J. Adv. Manuf. Technol., v.40, p.116-127, 2009.

GIANNOPOULOS, A. A.; MITSOURAS, D.; YOO, S.J. et al. Applications of 3D printing in cardiovascular diseases. Nat. Rev. Cardiol., v.13, p.701-718, 2016. 
MCDONALD, C.J., RYALL, C.J.; WIMPENNY, D.I. Medical models, the ultimate represesntations of a patient-specif anatomy. KWOUTERS, K. (Ed.). Rapid prototyping casebook. Trowbridge: Prfessional Engineerin Publising Limites, 2001. p.177-182.

MURAKAMI, T.; TAJIKA, Y.; UENO, H. et al. An integrated teaching method of gross anatomy and computed tomography radiology. Anat. Sci. Educ., v.7, p.438-449, 2014

MURPHY, S.V.; ATALA, A. 3D bioprinting of tissues and organs. Nat. Biotechnol., v.8, p.77385, 2014.

NEWE, A. Towards an easier creation of threedimensional data for embedding into scholarly 3D PDF (Portable Document Format) files. PeerJ, v.3, p.e794, 2015.

REIS, DAL.; GOUVEIA, BLR.; JUNIOR, JC. et al. Comparative assessment of anatomical details of thoracic limb of a horse to that of models produced via scanning and 3D printing. 3D Print Med., v.5, p.1-10, 2019

ROSSET, A.; SPADOLA, L.; RATIB, O. OsiriX: an open-source software for navigating in multidimensional DICOM images. J. Digit. Imaging., v.17, p.205-216, 2004.

SALMI, M.; PALOHEIMO, K.S.; TUOMI, J. et al. Accuracy of medical models made by additive manufacturing (rapid manufacturing). $J$. Craniomaxillofac. Surg., v.41, p.603, 2013.

SANDER, I.M.; MCGOLDRICK, M.T.; HELMS, M.N. et al. Three-dimensional printing of X-ray computed tomography datasets with multiple materials using open-source data processing. Anat. Sci. Educ., v.10, p.383-391, 2017

SONG, L.; MURPHY, S.V.; YANG, B. et al. Bladder acellular matrix and its application in bladder augmentation. Tissue Eng., v.20, p.163$172,2014$.

SU, W.; XIAO, Y.; HE, S. et al. Threedimentional printing models in congenital heart desease education for medical student: a controlled comparatibe stydu. BMC Med. Educ., v.19, p.1-6, 2018.

VISSER, J.; MELCHELS, F.P.; DHERT, W.J.; MALDA, J. Tissue printing; the potential application of 3D printing in medicine. Ned. Tijdschr. Geneeskd., v.157, p.52, 2013.

XU, T.; BINDER, W.K.; ALBANNA, M.Z et al. Hybrid printing of mechanically and biologically improved constructs for cartilage tissue engineering applications Biofabrication, v.5, p.015001, 2013.

ZHANG, X.; ZHANG, Y. Tissue engineering applications of three-dimensional bioprinting. Cell Biochem. Biophys., v.72, p.777-782, 2015. 